\title{
Dual Sliding Mode with PI Controller Based Switched Reluctance Motor Drive
}

\author{
Lahari Lakki, Venu Madhav Gopala
}

\begin{abstract}
In this paper, a Dual Sliding Mode with Proportional Integral (DSM-PI) controlled Switched Reluctance Motor drive circuit is proposed with closed loop speed control. An asymmetric half bridge converter is used to drive SRM which is fed by a front-end circuit. The dual sliding mode PI controller is utilized for better time response. With variable proportional $k_{p}$ and integral $k_{i}$ gains in DSM-PI controller the error generation value is altered with faster values making the speed of the motor to settle faster with reduced ripple and disturbances. The topology is modelled in MATLAB/Simulink environment and the simulation results on a three-phase 6/4 SRM are presented.
\end{abstract}

Index terms - Dual sliding mode proportional and integral controller, front-end circuit, Switched reluctance motor.

\section{INTRODUCTION}

Switched reluctance motor (SRM) is a simple and robust machine with neither rotor windings nor permanent magnets. SRM is doubly salient and singly excited machine. They are maintenance free and can work for long duration in difficult environments. The unique nature of Switched reluctance motor is its fault tolerant capability and the potential to carry on its operation even with faulted windings $[1,2]$ and hence is highly reliable. The switched reluctance motor efficiency is comparatively high. Research on the type of material used for construction of SRM to ameliorate it's efficiency is in [3].

The requirement of the rotor position to operate the motor without any hindrance was a drawback. Recently work on sensor less rotor position motor drives is developed where algorithms and pulse width modulation voltage control are used $[4,5]$.

Generally, a converter should be used for electric vehicle traction drives. Several types of such topologies have been

Developed like C-dump converter [6], etc. Of which Asymmetrical half bridge converter is mostly used converter circuit [7].

Switched Reluctance Motors(SRM) are mostly used in automobile applications like EV and PHEVs [8, 9].

For the reduction of Torque ripple many methods were introduced such as Direct Torque control[10], Direct Instantaneous Torque control[11] and the phase current control during commutation [12].

Sliding mode scheme will govern the gains of the proportional and integral controller based on the error of control loop and its derivative. Because of Sliding Mode

\footnotetext{
Revised Manuscript Received on September 10, 2019.

Lahari Lakki, PG Scholar, Department of EEE, Anurag Group of Institutions, Ghatkesar, Medak Dist., Telangana State, India.

(Email: lakki.lahari@gmail.com)

Venu Madhav Gopala, Professor, Department of EEE, Anurag Group of Institutions, Ghatkesar, Medak Dist., Telangana State, India.

(Email: venumadhaveee@cvsr.ac.in)
}

scheme there is some chattering which is diminished by using a transition rule which selects the PI controller gains when it reaches the steady state of the system. This new control technique is labeled as Dual Sliding Mode Proportional Integral[13].

In a normal PI controller the gains are fixed at one particular value. Distinctly in DSM-PI controller gain values are constantly changed according to the error generated.

In this paper, DSM-PI controller is used to derive current signal from speed error input. This DSM-PI controller continuously monitors $K_{p}$ and $K_{i}$ gains of proportional and integral gains respectively and consequently the response time is minimized. The main advantage of this scheme is settling time of the speed-time response is reduced with reduction in oscillations and disturbances. The simulation of the said concept on a three-phase 6/4 SRM validates the efficacy of using a DSM-PI controller.

\section{OPERATING PRINCIPLE}

A PI controller has proportional $K_{p}$ and integral $K_{i}$ gains fixed at one particular value, which remains constant even for higher value or lower value of error. Whereas in DSM-PI

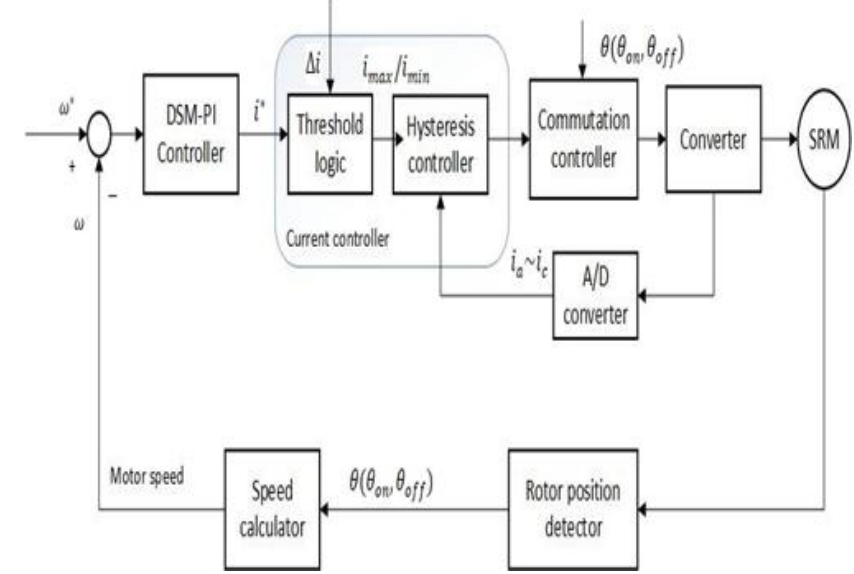

Fig.1 DSM-PI controlled SRM drive block diagram

controller the values of gains $K_{p}$ and $K_{i}$ are variable w.r.t. the error generated. If the speed error is high, value of gains $K_{p}$ and $K_{i}$ are increased and if it's low the gain values are decreased so as to reduce the settling time.

An ASH bridge converter is opted for switched reluctance motor drive because of its excellent stability, phase isolation, and ability to tolerate faults. A phase is said to be in excitation mode when that phase is energized. To energize every phase in sequence a front-end circuit is being 
used. This converter consists eight asymmetrical half-bridge legs, each leg consisting of insulated-gate bipolar transistor (IGBT) with a parallel diode.

The SRM drive using a DSM-PI controller with current regulation scheme block diagram is shown in Fig.1. The error in speed is preceded through dual sliding mode PI controller with current reference as the output. This reference current is then passed through threshold logic and hysteresis band blocks to obtain $i_{\text {max }}\left(i^{*}+\Delta i\right)$ and $i_{\text {min }}\left(i^{*}-\Delta i\right)$ to govern the phase turn-on region switching states. Turn-on angle and turn-off angle are fixed by position of rotor to determine commutation of phases.

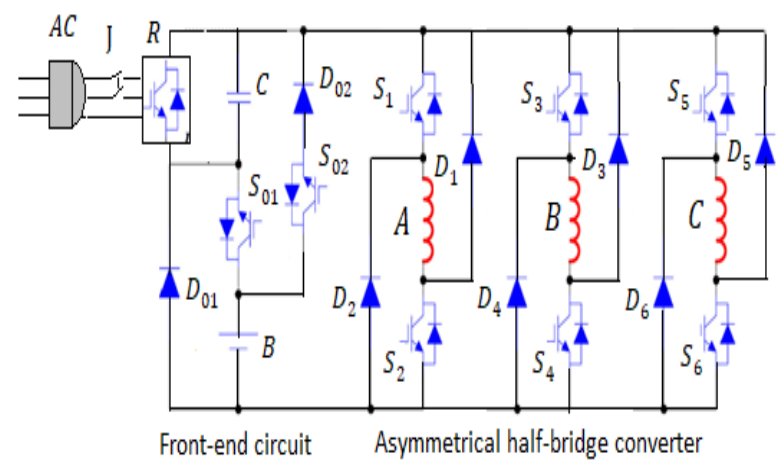

Fig.2. Front end circuit fed converter

\section{A. Front end circuit fed Converter}

A modular front end circuit fed conventional ASH bridge converter is shown in Fig. 2.It consists of a battery, threephase ac power supply, a rectifier, a capacitor and two IGBTs in parallel with diodes. By switching the two switches on and off in the circuit shown in fig. 2 different operating modes are obtained. The battery supplies DC power to asymmetrical bridge converter and to improve DClink voltage a capacitor is utilized. A relay $\mathrm{J}$ is used to disconnect the battery bank form the motor when the battery $\mathrm{B}$ is charging. The operating modes of the converter when the two switches are on and off are shown in Fig.3.

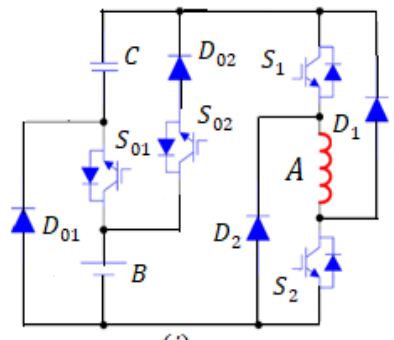

(i)

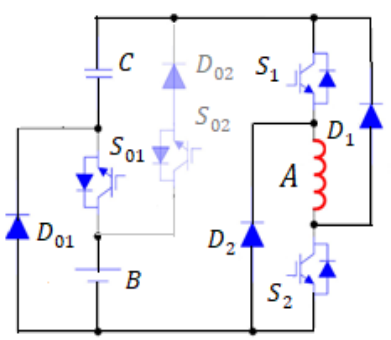

(iii)



(ii)



(iv)
Fig.3.Operating modes of the front-end circuit. (i)Mode 1 (ii)Mode 2

(iii)Mode 3 (iv)Mode 4


(ii)



(iv)

Fig. 4. Converter excitation modes.

(i) E1 (ii) E2 (iii) E3

(iv) Freewheeling mode.

\section{B. Excitation modes}

If the relay is switched $\mathrm{ON}$, the motor is operated by battery and three phase AC supply. In this position, the excitation modes of the converter under different voltages is shown in Fig.4(i),(ii) and (iv).Fig. 4(i) shows the E1 mode of A phase which is activated by battery and three-phase AC supply if switch $S_{01}$ is $\mathrm{ON}$ and switch $S_{02}$ is OFF. Fig. 4(ii) shows the E2 mode of A phase which is activated by threephase AC source if switch $S_{01}$ and switch $S_{02}$ are turned OFF. When switch $S_{1}$ is OFF and switch $S_{2}$ is ON, A phase is under zero-voltage loop i.e., freewheeling mode as shown in Fig. 4(iv).

If the relay is switched OFF and switch $S_{02}$ is turned ON, the battery is used to run the motor which are shown in Fig.4 (i) and (iii). Fig.4(i) shows the E1 mode when switch $S_{01}$ is $\mathrm{ON}$ and the additional charge $\mathrm{C}$ is supplied to the phase winding A for fast current building. Fig.4 (iii) shows the E3 mode when switch $S_{01}$ is turned OFF and phase $\mathrm{A}$ is activated by the battery.

\section{DESIGN AND MODELING OF DSM-PI CONTROL}

\section{A. SM-PI Control}

Sliding mode control is a nonlinear control having properties of robustness, accuracy and easy implementation. The two main benefits of sliding mode control are i. The dynamic behavior of system can be customized by choosing a specific sliding function. ii. The response of the closed loop becomes completely insensitive to specific uncertainties. This principle holds out to nonlinearity, disturbance and some parameter uncertainties which are bounded.

The SMC allows the control of nonlinear processes which are thread to heavy model uncertainties and external disturbances. 
The sliding surface is described by

$$
\sigma=c e_{\omega}+\dot{e_{\omega}}
$$

Where $e_{\omega}=\omega_{c}^{*}-\omega_{c}, \dot{e}_{\omega}$ is derivative and $c$ is constant.

Gains of the controller are calculated based on the formulas as

$$
\tilde{k}_{p}=\left[(1+\operatorname{sgn}(\sigma)) k_{p}^{+}-(1-\operatorname{sgn}(\sigma)) k_{p}^{-}\right]+k_{p}^{a v}
$$

$\tilde{k}_{i}=\left[(1+\operatorname{sgn}(\sigma)) k_{i}^{+}-(1-\operatorname{sgn}(\sigma)) k_{i}^{-}\right]+k_{i}^{a v}$

Where $k_{p}^{a v}, k_{i}^{a v}, k_{p}^{+}, k_{p}^{-}, k_{i}^{+}, k_{i}^{-}$are constants.

Wherein

$$
\operatorname{sgn}(\sigma)=\left\{\begin{array}{r}
1 \text { for } \sigma>0 \\
-1 \text { for } \sigma<0
\end{array}\right.
$$

\section{B. DSM-PI Control}

The hitch in the SM-PI control is that even though the performance is good in transient state, when steady state is reached it has a side effect. Because of sliding mode control switching laws which are used to determine the proportional and integral gains, chattering is originated. In order to mitigate the chattering the gains should be fixed. It is obtained by opting for the transition rule in controller structure.

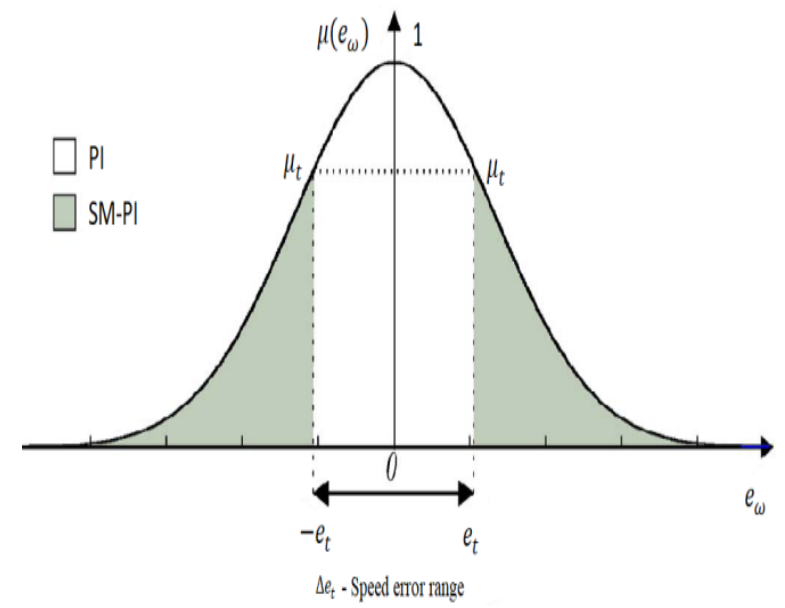

Fig.5.Transition criterion $\mu$ graph

Considering a Gaussian function,

$$
\mu\left(e_{\omega}\right)=e^{\frac{-e_{\omega}^{2}}{\lambda}}
$$

$\mu$ is the decision variable which selects between fixed and switching gains, $\lambda$ is Gaussian function parameter and $e_{\omega}$ is the speed error. If the limits of speed error are fixed i.e., $\Delta e_{t}$ the value of $\mu$ can be determined and the controller gains are selected (i.e., $\tilde{k}_{p}=k_{p}^{a v}$ and $\tilde{k}_{i}=k_{i}^{a v}$ ) shown in the fig. 5.
In the graph threshold value $\mu_{t}$ is allied to speed error $e_{\omega}$ where the transition occurs. By using equation (4) the value of $\mu$ is constantly calculated for speed error $e_{\omega}$.If the calculated value is less than $\mu_{t}$, the chosen control is SM-PI controller and if it is higher than $\mu_{t}$, controller with fixed gains is opted. The important aspect is the value of $\lambda$. For larger values of $\lambda$ the sensitivity of $\mu$ to the speed error $e_{\omega}$ is less and for lower values of $\lambda$ the sensitivity of $\mu$ to the speed error $e_{\omega}$ is high.

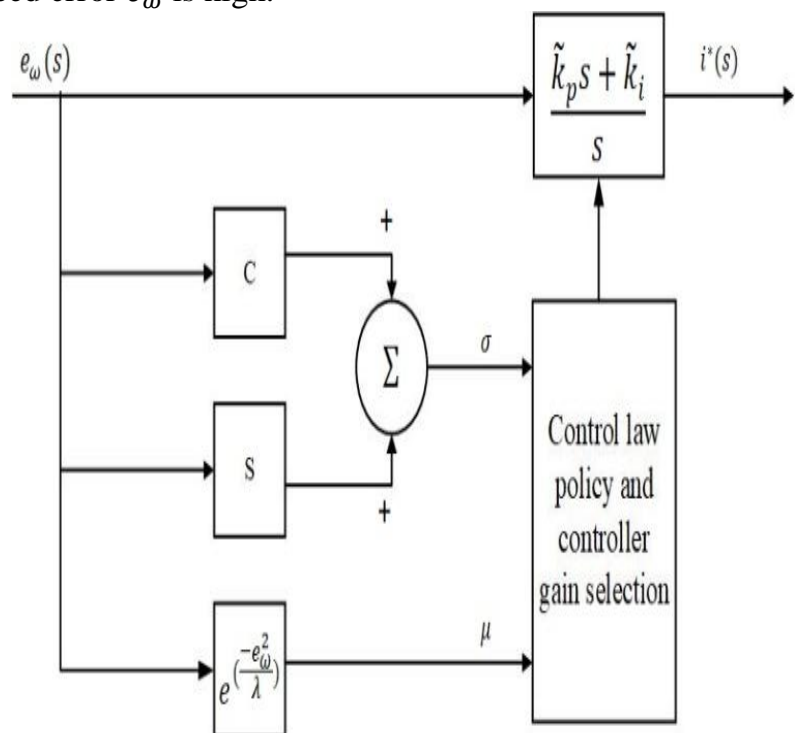

Fig.6. DSM-PI control scheme block diagram

The DSM-PI controller block diagram wherein values of $\tilde{k}_{p}$ and $\tilde{k}_{i}$ are calculated using equations (2),(3) shown in Fig.6.

\section{SIMULATION RESULTS}

The proposed topology of DSM-PI controller is tried on three-phase 6/4 switched reluctance motor. In MATLAB/Simulink, simulation model for the proposed concept is executed and the simulation model is shown in Fig.7. The SRM is operated by asymmetrical half bridge converter which consists of IGBTs. The drive signals for half bridge converter are supplied by the hysteresis controller and commutation controller based upon the speed and rotor position of SRM. 




Fig.8 Front-end circuit Simulation model

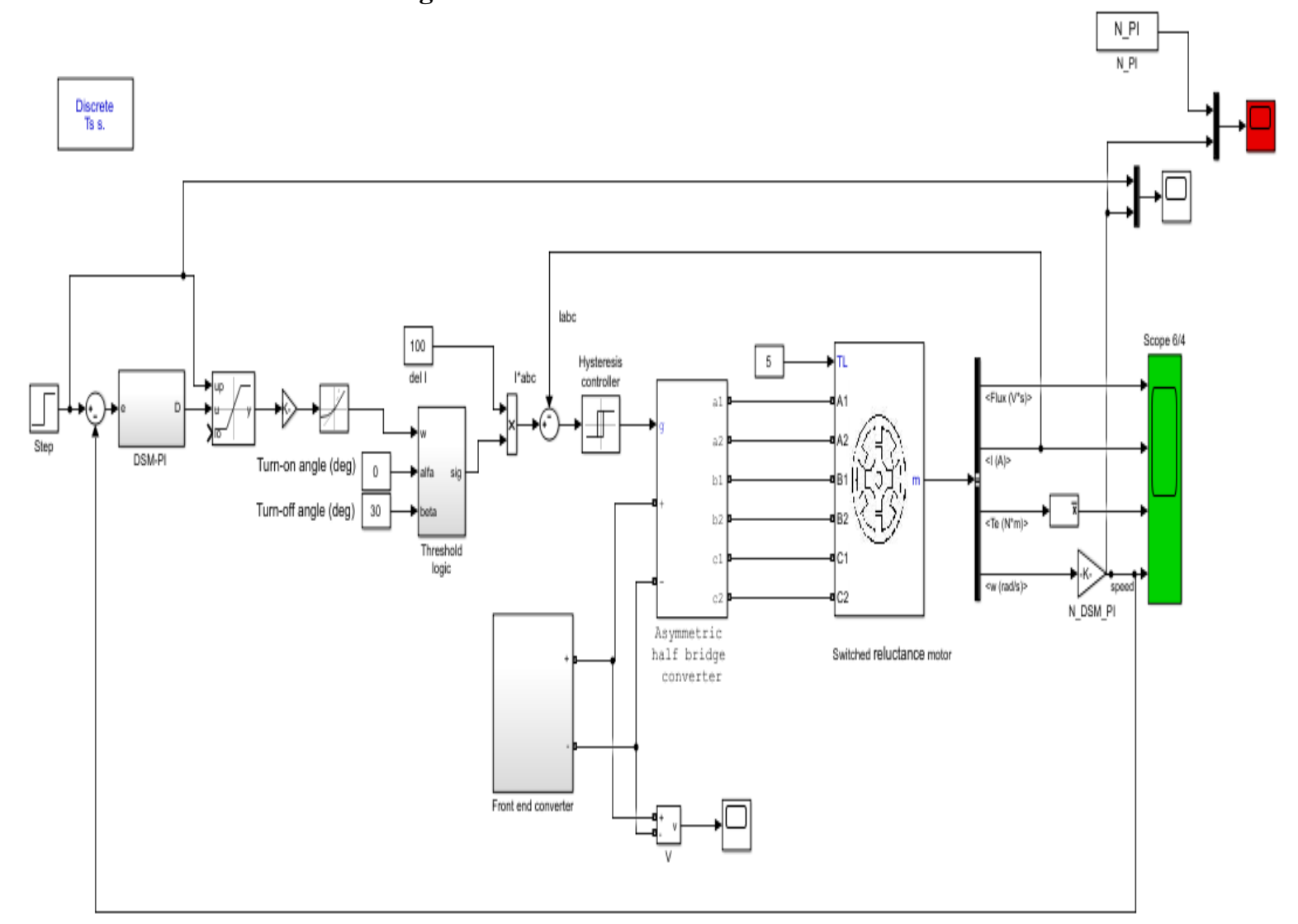

Fig.7.SRM drive simulation model 
The half bridge converter is linked to a front end circuit and it's simulation model is shown in Fig. 8.The three-phase AC power supply is of $230 \mathrm{v}, 50 \mathrm{~Hz}$. The battery employed is a Lithium ion battery with $200 \mathrm{v}, 50 \mathrm{Ah}$ rated capacity. The initial State-of-charge of the battery is set to $80 \%$.

$\left\langle\right.$ Flux $\left(\mathrm{V}^{\star} \mathrm{s}\right)>$


Fig. 9.Flux and Current of SRM drive

The flux of three phase switched reluctance motor and it's instantaneous currents are shown in Fig.9.

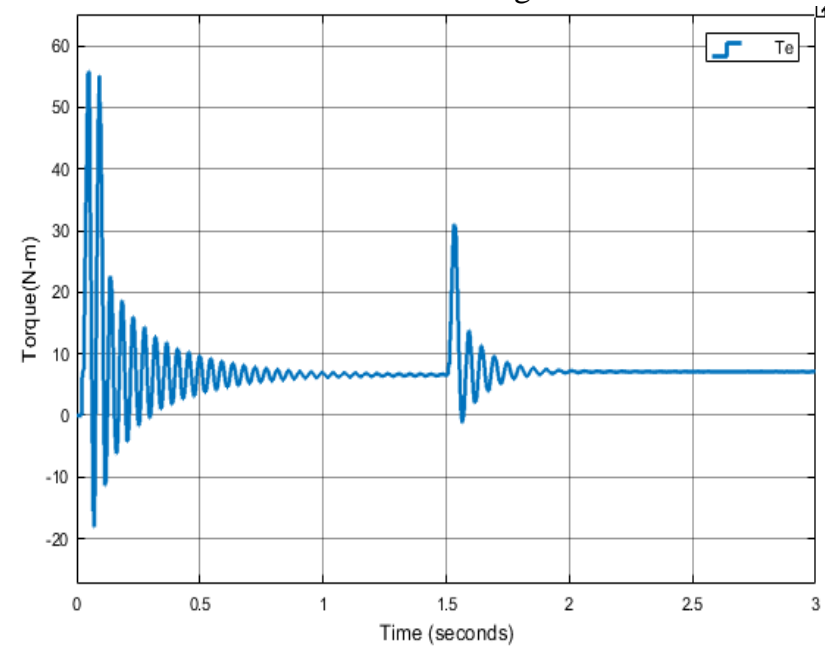

Fig.10 Torque of SRM drive

A step input is used which increases the speed of the motor from $1500 \mathrm{rpm}$ to $2000 \mathrm{rpm}$ at $1.5 \mathrm{~seconds}$. The torque of SRM at 1500rpm and 2000rpm is shown in Fig. 10.The disturbance at 1.5 seconds is the consequence for the sudden increase in the speed of the SRM.

Fig. 11 shows Torque vs time response of the PI and DSM-PI controlled SRM drive. The damping in the oscillations is large in DSM-PI controlled system when compared to PI controlled system.

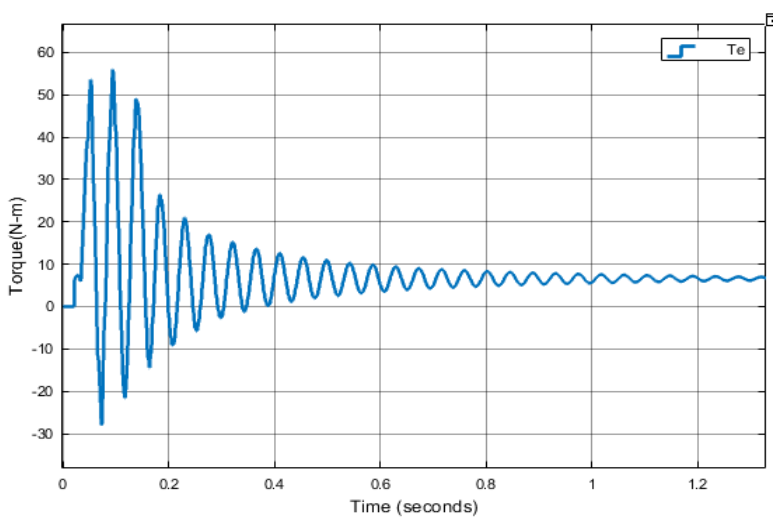

(a)

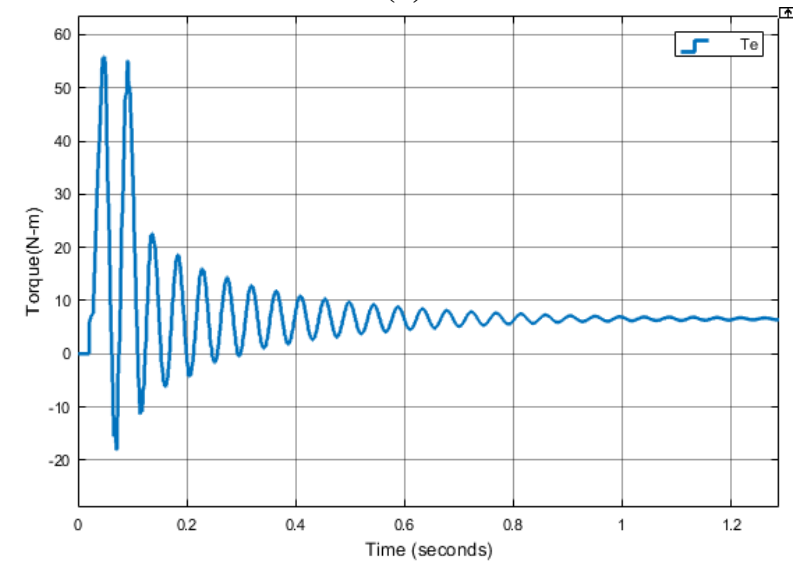

(b)

Fig. 11.Torque (a) PI controlled (b) DSM-PI controlled
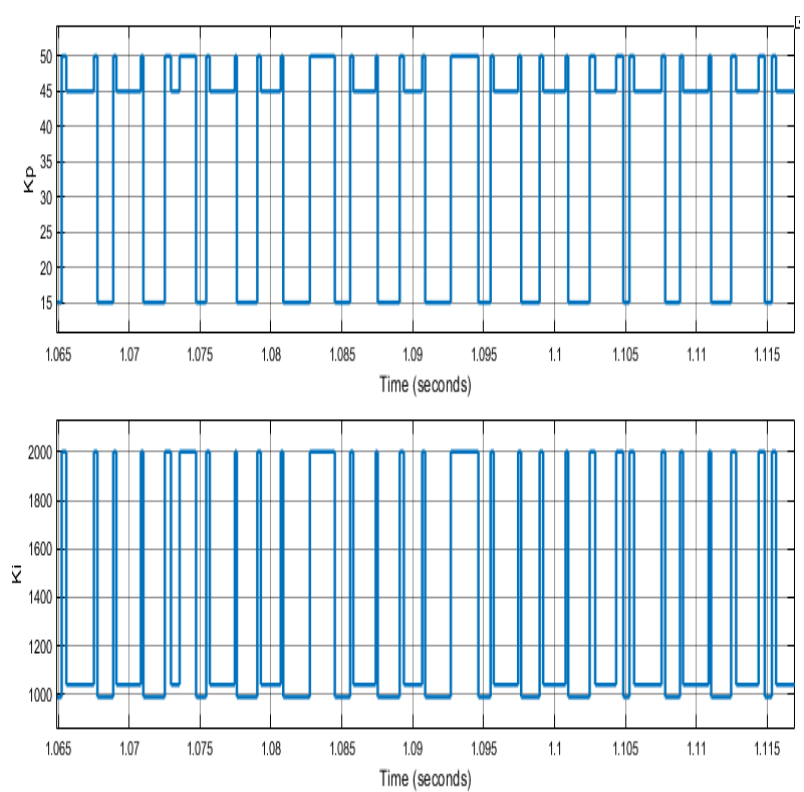

Fig.12.DSM-PI controller gains $\boldsymbol{k}_{p}$ and $\boldsymbol{k}_{i}$ 
The Dual sliding mode PI controller gains are shown in Fig.12.The values of DSM-PI controller are in Table-I.

Table-i

Parameters dsm-pi controller

\begin{tabular}{|l|l|l|}
\hline$k_{p}^{+}=10$ & $k_{p}^{-}=5$ & $k_{p}^{a v}=25$ \\
\hline$k_{i}^{+}=20$ & $k_{i}^{-}=5$ & $k_{i}^{a v}=1000$ \\
\hline$c=100$ & $\lambda=500$ & $\mu_{t}=0.98$ \\
\hline
\end{tabular}

The speed-time response comparison between normal PI controlled and DSM-PI controlled SRM is shown in Fig.13.The settling time for PI controlled SRM drive is $1.4 \mathrm{sec}$ whereas for a DSMPI controlled system it is $1 \mathrm{sec}$. The frequent change in the proportional $k_{p}$ and integral $k_{i}$ gains according to the speed error consequently results in the reduced oscillations and the settling time is decreased causing the speed of motor to settle fast.



Fig. 13 Speed comparison of SRM drive with PI and DSM-PI controllers

\section{CONCLUSION}

A dual sliding mode proportional and integral controller is used to operate switched reluctance motor drive in this paper. This modular front-end circuit fed SRM drive has different operating modes which are obtained by switching IGBTs ON and OFF. With this topology $K_{p}$ and $K_{i}$ gains can be changed with respect to the error. If the error is high, gains of $K_{p}$ and $K_{i}$ are increased and if it's low the gains are decreased. With variable $K_{p}$ and $K_{i}$ values, if the error is high the $K_{p}$ and $K_{i}$ values are increased improving the time response of the drive and when the error is low the $K_{p}$ and $K_{i}$ values are decreased reducing the oscillations and disturbances. Hence the DSM-PI controller makes the speed response settle faster and with lower oscillations and disturbances. The simulation results confirm the concept of proposed topology.

\section{REFERENCES}

1. Stephens, Charles M. "Fault detection and management system for fault-tolerant switched reluctance motor drives." IEEE Transactions on Industry Applications 27, no. 6 (1991): 1098-1102.

2. Sun, Qingguo, Jianhua Wu, Chun Gan, and Jifeng Guo. "Modular full-bridge converter for three-phase switched reluctance motors with integrated fault-tolerance capability." IEEE Transactions on Power Electronics 34, no. 3 (2018): 2622-2634.
3. Hayashi, Hiroaki, Akira Chiba, and Tadashi Fukao "Efficiency comparison of switched reluctance motors with low loss materials." In 2007 IEEE Power Engineering Society General Meeting, pp. 1-6. IEEE, 2007.

4. Gallegos-Lopez, Gabriel, Philip C. Kjaer, and Timothy JE Miller. "A new sensorless method for switched reluctance motor drives." IEEE Transactions on Industry Applications 34, no. 4 (1998): 832-840.

5. Hayati, Ali, Alireza Siadatan, and Peymaneh Shirazi. "A novel simple sensor less algorithm in order to drive Switched Reluctance Motor from standstill to high speed." In The 6th Power Electronics, Drive Systems \& Technologies Conference (PEDSTC2015), pp. 655-660. IEEE, 2015.

6. Babu, B. Prebin, and M. V. Jayan. "A high efficiency novel C-dump topology based converter for SRM." In 2017 IEEE International Conference on Power, Control, Signals and Instrumentation Engineering (ICPCSI), pp. 1170-1175. IEEE, 2017.

7. Niakinezhad, Mehdi, Inam Ullah Nutkani, and Nuwantha Fernando. "A New Modular Asymmetrical Half-Bridge Switched Reluctance Motor Integrated Drive for Electric Vehicle Application." In 2018 IEEE 27th International Symposium on Industrial Electronics (ISIE), pp. 10031010. IEEE, 2018.

8. Qianfan, Zhang, Cui Shumei, and Tian Xinjia. "Hybrid switched reluctance motor applied in electric vehicles." In 2007 IEEE Vehicle Power and Propulsion Conference, pp. 359-363. IEEE, 2007.

9. Ma, Mingyao, Zhongyi Chang, Yihua Hu, Fei Li, Chun Gan, and Wenping Cao. "An integrated switched reluctance motor drive topology with voltage-boosting and on-board charging capabilities for plug-in hybrid electric vehicles (PHEVs)." IEEE Access 6 (2017): 15501559.

10. Ye, Jin, Berker Bilgin, and Ali Emadi. "An extendedspeed low-ripple torque control of switched reluctance motor drives." IEEE Transactions on Power Electronics 30, no. 3 (2014): 1457-1470.

11. $\mathrm{Xu}$, Aide, Wen Zhang, and Ping Ren. "Comparison of torque ripple reduction for switched reluctance motor based on DTC and DITC." In 2018 13th IEEE Conference on Industrial Electronics and Applications (ICIEA), pp. 1727-1732. IEEE, 2018.

12. Ye, Wei, Qishuang Ma, and Jiefeng Hu. "Torque ripple minimization of switched reluctance motors by controlling the phase currents during commutation." In 2014 17th International Conference on Electrical Machines and Systems (ICEMS), pp. 1866-1870. IEEE, 2014.

13. de Araujo Ribeiro, Ricardo Lúcio, Thiago de Oliveira Alves Rocha, Raphaell Maciel de Sousa, Euzeli Cipriano dos Santos, and Antonio Marcus Nogueira Lima. "A robust dc-link voltage control strategy to enhance the performance of shunt active power filters without harmonic detection schemes." IEEE Transactions on Industrial Electronics 62, no. 2 (2014): 803-813. 